\title{
Virtual Flux Predictive Direct Power Control of Five-level T-type Multi-terminal VSC-HVDC System
}

\author{
Ahmed Reguig Berra ${ }^{1 *}$, Said Barkat ${ }^{1}$, Mansour Bouzidi ${ }^{2,3}$ \\ ${ }^{1}$ Laboratory of Electrical Engineering, Faculty of Technology, University Mohamed Boudiaf of M'sila, P. O. B. 166, M'sila, 28000, \\ Algeria \\ 2 Department of Electronics and Communications, Faculty of New Information and Communication Technologies, Kasdi Merbah \\ University, P. O. B. 511, Ouargla, 30000, Algeria \\ ${ }^{3}$ Department of Electrical Engineering, Faculty of Engineering Sciences, Djillali Liabes University of Sidi Bel Abbes, P. O. B. 89, \\ Sidi-Bel-Abbès, 22000, Algeria \\ *Corresponding author, e-mail: ahmed.berra@univ-msila.dz
}

Received: 24 May 2019, Accepted: 10 October 2019, Published online: 08 January 2020

\begin{abstract}
This paper proposes a Virtual Flux Predictive Direct Power Control (PDPC) for a five-level T-type multi-terminal Voltage Source Converter High Voltage Direct Current (VSC-HVDC) transmission system. The proposed PDPC scheme is based on the computation of the average voltage vector using a virtual flux predictive control algorithm, which allows the cancellation of active and reactive power tracking errors at each sampling period. The active and reactive power can be estimated based on the virtual flux vector that makes AC line voltage sensors not necessary. A constant converter switching frequency is achieved by employing a multilevel space vector modulation, which ensures the balance of the DC capacitor voltages of the five-level t-type converters as well. Simulation results validate the efficiency of the proposed control law, and they are compared with those given by a traditional direct power control. These results exhibit excellent transient responses during range of operating conditions.
\end{abstract}

\section{Keywords}

High Voltage Direct Current, five-level T-type converter, multi-level space vector modulation, virtual flux estimator, predictive direct power control

\section{Introduction}

The traditional way of transporting the power using AC transmission systems has been recognized as the most available technology, but for long distance HVDC transmission systems are gaining much attention right now [1]. This is because; HVDC not only has low power losses especially for long transmission but also it is capable to transmit higher power over longer distances. Not only has that, but thanks to its high efficiency and flexible control, HVDC system been played an increasingly important role in asynchronous networks [2-5].

The concept of HVDC system can be categorized as Line Commutated Converter HVDC (LCC-HVDC) system and Voltage Sourced Converter HVDC (VSC-HVDC) system [6]. LCC based on thyristors has the drawbacks of drawing considerable amounts of reactive power to the thyristor valves, generating a large number of low order harmonics, and it requires a strong connection to the AC network.

In addition to that, the power flow reversal with LCCHVDC is limited, and it is performed by changing the DC voltage polarity [7, 8]. Recently, the advanced power electronic devices with turn-off capability like Insulated Gate Bipolar Transistor (IGBT) have led to the development of VSC based HVDC transmission. The principal advantages of VSC-HVDC system is an independent control of active and reactive powers and faster power flow control with benefits in grid stability, bidirectional active power transmission without changing DC voltage polarity, operation with a weak or passive AC system, and no line commutation problems [4, 8, 9]. Specifically, multi-terminal HVDC (MTDC) is ideal for offshore platforms and it can also be used for connecting national AC grids with different frequencies [10]. A multi-terminal VSC-HVDC system consists of more than two converters connected through DC line cables and sharing the same DC bus. It has 
advantages over point-to-point HVDC transmission system one in many aspects such as control flexibility, security, reliability, and economy $[9,11]$.

Many recent works have been done in HVDC converter systems, some of them using full back-to-back multilevel diode clamped converters [12] which have well known attractive features in high voltage and high power applications [13]. Indeed, multilevel converters have shown some significant advantages over traditional two-level converters. They provide higher power quality at the AC side, can operate at higher $\mathrm{AC}$ voltage levels and minimize or even eliminate the interface transformer, and reduce switching losses [12-15]. Generally, multilevel VSC can be divided into various topologies such as, Neutral Point Clamped (NPC), Flying Capacitor (FC), Cascade H-Bridge (CHB) and Modular Multilevel Converters (MMC). Another interesting multilevel topology is proposed in [16-20], known as Packed U Cell (PUC). This topology is a combination of FC and $\mathrm{CHB}$ with reduced number of capacitors and semiconductors. However, PUC topology requires complex controller to balance capacitor voltages. Within the class of multilevel converters, T-type converter is introduced as a new topology. This converter is proposed for high-efficiency systems that allow operation at reducing converter cost. During the operating intervals, the number of conducting semiconductors is smaller, representing a reduction in total losses. It presents fewer semiconductors because it does not need clamped diodes, and simple power circuit; consequently, a higher efficiency is achieved [21, 22].

Various control strategies have been proposed to control VSC-HVDC system [12, 23-25]. Over the past few years, an interesting emerging control technique known as Direct Power Control (DPC) is proposed [4].

The main idea of DPC proposed in [26] is similar to the well-known Direct Torque Control (DTC) proposed for induction motors. In the DPC approach, the active and reactive powers variables are directly controlled in a manner analogous to torque and flux control in motor drives applications [26]. In DPC, there are no internal current loops or modulator block. Indeed, the converter switching states are selected via a switching table [9]. The main drawbacks of this control scheme are the variable switching frequency and fast sampling required for a digital implementation of the hysteresis controllers [27]. These drawbacks can be eliminated by replacing the hysteresis comparators and the switching table by a PI controllers and Space Vector Modulation (SVM) approach. This method is considered an effective way to reduce power ripple and it also has the advantage of a fixed switching frequency [9].
Recently, a predictive direct power control algorithm with SVM approach has been proposed [27, 28]. The idea is to combine the conventional DPC algorithm with the model predictive control algorithm. The main advantages of the proposed control are: no need to use predefined switching table, PI-based active and reactive power control loops are not necessary, high transient dynamic and constant switching frequency $[27,28]$. However, continuous measurements of the powers quantities are necessary, which requires a high number of sensors.

A Virtual Flux (VF) concept was proposed in [29], which basically relates the grid voltage and the $\mathrm{AC}$ side inductors to a virtual AC motor. The use of VF gives advantages like system simplification, isolation between control and power circuit part, reliability, and cost reduction [26, 28].

This paper present a direct power control scheme with virtual flux concept of five-level T-type multi-terminal VSC-HVDC transmission system based on a predictive approach. The proposed predictive DPC technique operates with constant switching frequency using multilevel SVM. The control objectives are:

1. controlling the active and reactive power of each network sides,

2. generating sinusoidal line currents,

3. regulating the DC bus voltage of the multi-terminal VSC-HVDC system,

4. balancing DC capacitors of the DC buses.

The rest of the paper is organized as follows. In Section 2, a mathematical model of the five-level T-type VSC-HVDC transmission system is presented. Section 3 describes the proposed control method. Simulation results are presented and illustrated in Section 4. At last, conclusions are drawn in Section 5.

\section{System configuration}

\subsection{Power circuit description}

Fig. 1 shows a schematic representation of a multi-terminal HVDC transmission system connecting AC grid to tow offshore wind farms modelled as alternative sources. The general structure of VSC-MTDC system is composed by tow VSCs based on five-level T-type at the rectifier sides and one terminal based on five-level T-type at the inverter side. The two independent wind farms inject the power produced by the wind farms into the DC grid. A DC cable is used to join the terminals to the sending end. Electricity will be transferred through a DC cable to the receiving end point, and finally reaching inverter terminal. At the inverter terminal, electricity will be converted from DC back to AC. 


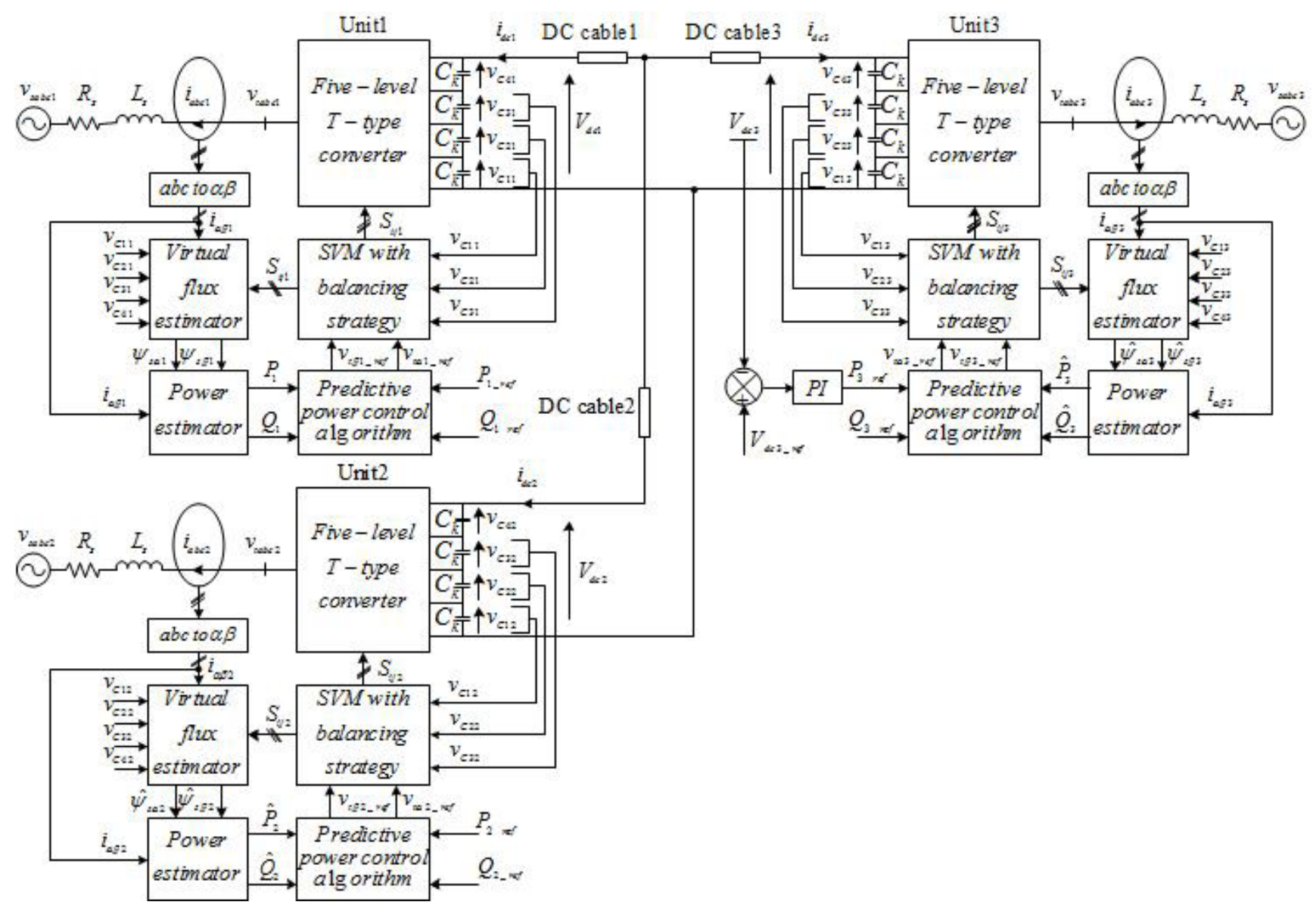

Fig. 1 Configuration of the proposed MTDC system

\subsection{Modeling and analysis of five-level T-type converter} Fig. 2 shows a schematic diagram of a five-level T-type converter in which the DC-link consists of four capacitors $C_{1 k}, C_{2 k}, C_{3 k}$ and $C_{4 k}$.

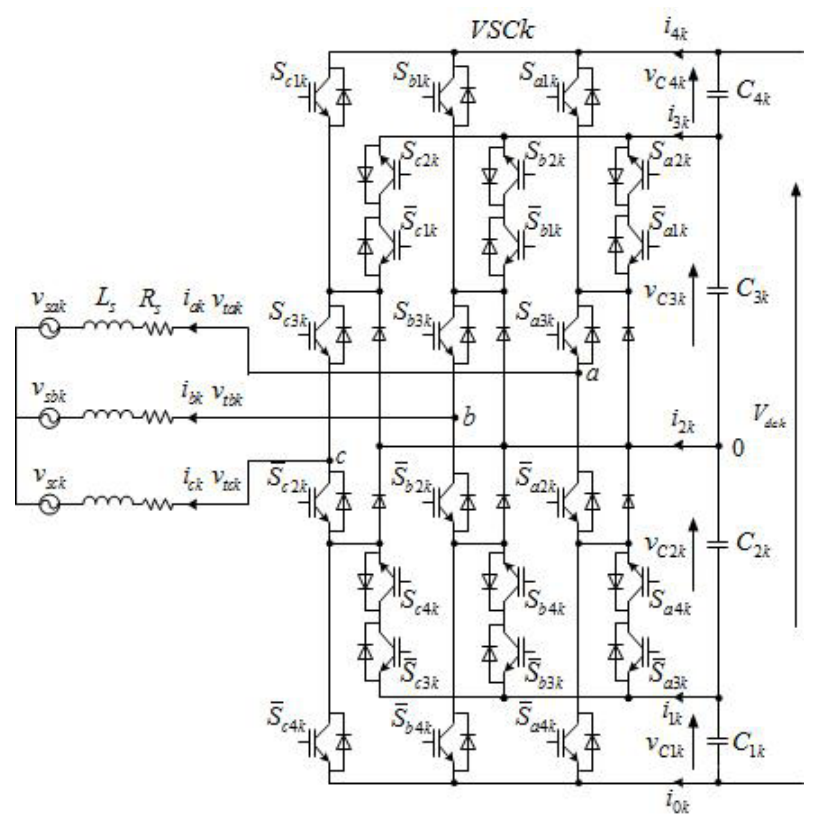

Five-level T-type topology is composed by dual threelevel T-type modules. Each leg consists of eight active switches and two clamping diodes [22]. These switches operate in switch pairs $\left(S_{i j k}, \bar{S}_{i j k}\right), i=a, b, c$, and $j=1,2,3,4$ and in a complementary manner.

Considering voltage of node " 0 " as the reference voltage, the switching combinations to synthesize different voltage levels of the five-level T-type converter are summarized in Table 1.

Table 1 The arrangement of channels Definition of T-type converter switching states

\begin{tabular}{ccccccccc}
\hline$S_{i 1 k}$ & $S_{i 2 k}$ & $S_{i 3 k}$ & $S_{i 4 k}$ & $\bar{S}_{i 1 k}$ & $\bar{S}_{i 2 k}$ & $\bar{S}_{i 3 k}$ & $\bar{S}_{i 4 k}$ & $v_{i 0 k}$ \\
\hline 1 & 1 & 1 & 1 & 0 & 0 & 0 & 0 & $v_{C 3 k}+v_{C 4 k}$ \\
0 & 1 & 1 & 1 & 1 & 0 & 0 & 0 & $v_{C 3 k}$ \\
0 & 0 & 1 & 1 & 1 & 1 & 0 & 0 & 0 \\
0 & 0 & 0 & 1 & 1 & 1 & 1 & 0 & $-v_{C 2 k}$ \\
0 & 0 & 0 & 0 & 1 & 1 & 1 & 1 & $-\left(v_{C 1 k}+v_{C 2 k}\right)$ \\
\hline
\end{tabular}

Fig. 2 Main circuit of five-level T-type converter $(k=1,2,3)$ 
The switching functions of the five-level T-type converter of Fig. 2 are expressed as

$$
\begin{aligned}
& F_{x 4 k}=S_{x 4 k} S_{x 3 k} S_{x 2 k} S_{x 1 k} \\
& F_{x 3 k}=S_{x 4 k} S_{x 3 k} S_{x 2 k} \bar{S}_{x 1 k} \quad x=a, b, c . \\
& F_{x 2 k}=S_{x 4 k} S_{x 3 k} \bar{S}_{x 2 k} \bar{S}_{x 1 k} \\
& F_{x 1 k}=S_{x 4 k} \bar{S}_{x 3 k} \bar{S}_{x 2 k} \bar{S}_{x 1 k}
\end{aligned}
$$

The expressions of instantaneous converters phase voltages are given by

$$
\begin{aligned}
& v_{t a k}=\sum_{j=1}^{4}\left[\left(2 F_{g j k}-F_{b j k}-F_{c j k}\right)\left(\sum_{i=1}^{j} v_{c i k}\right)\right] \\
& v_{b b k}=\sum_{j=1}^{4}\left[\left(2 F_{b j k}-F_{a j k}-F_{c j k}\right)\left(\sum_{i=1}^{j} v_{c i k}\right)\right] \\
& v_{c k k}=\sum_{j=1}^{4}\left[\left(2 F_{c j k}-F_{a j k}-F_{b j k}\right)\left(\sum_{i=1}^{j} v_{c i k}\right)\right]
\end{aligned}
$$

where $v_{t x k}, x=a, b, c$ are the output voltages of the T-type converter and $v_{C j k}$ are the capacitor voltages of $C_{j k}$.

The dynamic equations of $\mathrm{AC}$ side in $\alpha \beta$ reference are expressed as

$$
\begin{aligned}
& \frac{d i_{\alpha k}}{d t}=\frac{1}{L_{s}}\left(v_{t \alpha k}-v_{s \alpha k}-R_{s} i_{\alpha k}\right) \\
& \frac{d i_{\beta k}}{d t}=\frac{1}{L_{s}}\left(v_{t \beta k}-v_{s \beta k}-R_{s} i_{\beta k}\right)
\end{aligned}
$$

where $i_{\alpha k}$ and $i_{\beta k}$ are the line current components, $v_{t a k}$ and $v_{t \beta k}$ are the converter output voltage components, $v_{s a k}$ and $v_{s \beta k}$ are the $\alpha \beta$ axes components of the source voltage vector and $R_{s}, L_{s}$ represent series connected phase reactors.

On the other hand, the DC side is governed by

$$
\frac{d V_{d c k}}{d t}=\frac{i_{d c k}}{C_{e q k}}-\frac{P_{k}}{C_{e q k} V_{d c k}}
$$

where $V_{d c k}$ is the DC bus voltage, $i_{d c k}$ is the current of the line transmission, $P_{k}$ is the power of DC-side and $C_{e q}=C_{j k} / 4, \quad j=1,2,3,4$ is the DC-link equivalent capacitance.

\section{Virtual flux predictive direct power control}

Fig. 1 shows the schematic diagram of the proposed virtual flux PDPC strategy for multi-terminal VSC-HVDC system. The first and second converters are responsible to control active power exchanges; the third converter is devoted to regulate the $\mathrm{DC}$ voltage, while the reactive power is controlled by all ends [27, 28].

The estimated active and reactive powers and their references are used as input variables of the predictive control algorithm block. At the beginning of each sampling period, the average voltage vector, which allows cancellation of instantaneous active and reactive power tracking errors at the end of the sampling period, is computed.
Then, the five-level SVM technique is used to generate a sequence of switching states of each converter to achieve the control objective with constant switching frequency.

The virtual flux concept is based on a duality with induction motor fed by a PWM inverter, where $R_{s}$ and $L_{s}$ represent the stator resistance and leakage inductance of the virtual motor [28].

The virtual flux estimator is based on Eq. (5)

$$
\begin{aligned}
& \psi_{s \alpha k}=\int v_{s \alpha k} d t \\
& \psi_{s \beta k}=\int v_{s \beta k} d t
\end{aligned}
$$

In general, $R_{s}$ can be neglected. So, the relation between flux and voltage can be derived as

$\psi_{s \alpha k}=\int v_{t \alpha k} d t-L_{s} i_{\alpha k}$.
$\psi_{s \beta k}=\int v_{t \beta k} d t-L_{s} i_{\beta k}$.

The estimated active and reactive powers can be expressed by the following formulas

$$
\begin{aligned}
& P_{k}=\omega_{k}\left(\psi_{s \alpha k} i_{\beta k}-\psi_{s \beta k} i_{\alpha k}\right) \\
& Q_{k}=\omega_{k}\left(\psi_{s \alpha k} i_{\alpha k}+\psi_{s \beta k} i_{\beta k}\right)
\end{aligned}
$$

where $\omega_{k}$ is the angular frequency.

The active and reactive power derivatives are given as follows

$$
\begin{aligned}
& \frac{d P_{k}}{d t}=\omega_{k}\left(\frac{d \psi_{\alpha k}}{d t} i_{\beta k}+\psi_{\alpha k} \frac{d i_{\beta k}}{d t}-\frac{d \psi_{\beta k}}{d t} i_{\alpha k}-\psi_{\beta k} \frac{d i_{\alpha k}}{d t}\right) \\
& \frac{d Q_{k}}{d t}=\omega_{k}\left(\frac{d \psi_{\alpha k}}{d t} i_{\alpha k}+\psi_{\alpha k} \frac{d i_{\alpha k}}{d t}+\frac{d \psi_{\beta k}}{d t} i_{\beta k}+\psi_{\beta k} \frac{d i_{\beta k}}{d t}\right)
\end{aligned} .
$$

For three-phase balanced system, the following relations can be written as

$$
\begin{aligned}
& \psi_{\alpha k}=\frac{v_{t \beta k}}{\omega_{k}}, \quad \frac{d \psi_{\alpha k}}{d t}=-\omega_{k} \psi_{\beta k} \\
& \psi_{\beta k}=-\frac{v_{t \alpha k}}{\omega_{k}}, \quad \frac{d \psi_{\alpha k}}{d t}=-\omega_{k} \psi_{\beta k}
\end{aligned}
$$

By replacing powers by their terms, Eq. (8) becomes

$$
\begin{aligned}
& \frac{d P_{k}}{d t}=-\omega_{k} Q_{k}+\frac{\omega_{k}}{L_{s}} {\left[\psi_{\alpha k}\left(-R_{s} i_{\beta k}-\omega_{k} \psi_{\alpha k}+v_{t \beta k}\right)\right.} \\
&\left.-\psi_{\beta k}\left(-R_{s} i_{\alpha k}+\omega_{k} \psi_{\beta k}+v_{t \alpha k}\right)\right] . \\
& \frac{d Q_{k}}{d t}=\omega_{k} P_{k}+\frac{\omega_{k}}{L_{s}} {\left[\psi_{\alpha k}\left(-R_{s} i_{\alpha k}+\omega_{k} \psi_{\beta k}+v_{t \alpha k}\right)\right.} \\
&\left.+\psi_{\alpha k}\left(-R_{s} i_{\beta k}-\omega_{k} \psi_{\alpha k}+v_{t \beta k}\right)\right]
\end{aligned}
$$

If the sampling period $T_{e}$ is infinitely small compared with the fundamental period. The discretization of Eq. (10) yields 


$$
\begin{aligned}
\frac{\left(P_{k}(k)+\Delta P_{k}(k)\right)-P_{k}(k)}{T_{e}}= & -\omega_{k} Q_{k}+\frac{\omega_{k}}{L_{s}} \\
& {\left[\psi_{\alpha k}\left(-R_{s} i_{\beta k}-\omega_{k} \psi_{\alpha k}+v_{t \beta k}\right)\right.} \\
& \left.-\psi_{\beta k}\left(-R_{s} i_{\alpha k}+\omega_{k} \psi_{\beta k}+v_{t \alpha k}\right)\right] \\
\frac{\left(Q_{k}(k)+\Delta Q_{k}(k)\right)-Q_{k}(k)}{T_{e}}= & \omega_{k} P_{k}+\frac{\omega_{k}}{L_{s}} \\
& {\left[\psi_{\alpha k}\left(-R_{s} i_{\alpha k}+\omega_{k} \psi_{\beta k}+v_{t \alpha k}\right)\right.} \\
& \left.+\psi_{\alpha k}\left(-R_{s} i_{\beta k}-\omega_{k} \psi_{\alpha k}+v_{t \beta k}\right)\right]
\end{aligned}
$$

where $\Delta P_{k}(k)$ and $\Delta Q_{k}(k)$ are the variations in active and reactive powers, given by

$$
\begin{aligned}
& \Delta P_{k}(k)=P_{k}(k+1)-P_{k}(k) \\
& \Delta Q_{k}(k)=Q_{k}(k+1)-Q_{k}(k)
\end{aligned} .
$$

From Eq. (12), predictive values of the powers can be expressed as follows

$$
\begin{aligned}
P_{k}(k+1)=T_{e}\left[-\omega_{k} Q_{k}(k)+\frac{\omega_{k}}{L_{s}}\right. & {\left[\psi_{\alpha}(k)\left(-R_{s} i_{\beta}(k)-\omega_{k} \psi_{\alpha}(k)+v_{t \beta}(k)\right)\right.} \\
& \left.\left.-\psi_{\beta}(k)\left(-R_{s} i_{\alpha}(k)+\omega_{k} \psi_{\beta}(k)+v_{t \alpha}(k)\right)\right]\right] \\
+P_{k}(k) & \\
Q_{k}(k+1)=T_{e}\left[\omega_{k} P_{k}(k)+\frac{\omega_{k}}{L_{s}}\right. & {\left[\psi_{\alpha}(k)\left(-R_{s} i_{\alpha}(k)+\omega_{k} \psi_{\beta}(k)+v_{t \alpha}(k)\right)\right.} \\
& \left.\left.+\psi_{\beta}(k)\left(-R_{s} i_{\beta}(k)-\omega_{k} \psi_{\alpha}(k)+v_{t \beta}(k)\right)\right]\right]
\end{aligned}
$$$$
+Q_{k}(k)
$$

Since the control objective is to force active and reactive powers to be equal to their reference values at the next sampling period, and neglecting the effect of the series resistance, Eq. (13) can be rewritten as follows

$$
\begin{aligned}
{\left[\begin{array}{c}
P_{k_{-} r e f}(k+1)-P_{k}(k) \\
Q_{k_{-} r e f}(k+1)-Q_{k}(k)
\end{array}\right] } & =T_{e} \omega_{k}\left[\begin{array}{c}
-Q_{k}(k) \\
P_{k}(k)
\end{array}\right]+\frac{T_{c} \omega_{k}}{L_{s}} \\
& {\left[\begin{array}{cc}
-\psi_{\beta k}(k) & \psi_{\alpha k}(k) \\
\psi_{\alpha k}(k) & \psi_{\beta k}(k)
\end{array}\right] } \\
& {\left[\begin{array}{l}
v_{t \beta k}(k)+\omega_{k} \psi_{\beta k}(k) \\
v_{t \alpha k}(k)-\omega_{k} \psi_{\alpha k}(k)
\end{array}\right] . }
\end{aligned}
$$

By replacing $P_{k \text { ref }}(k+1)$ and $Q_{k r e f}(k+1)$ by their expressions, Eq. (14) becomes

$$
\begin{aligned}
& {\left[\begin{array}{c}
e_{p k}(k)+\Delta P_{k_{-} r e f}(k) \\
e_{q k}(k)+\Delta Q_{k_{-} r e f}(k)
\end{array}\right]=T_{e} \omega_{k}\left[\begin{array}{c}
-Q_{k}(k) \\
P_{k}(k)
\end{array}\right]+\frac{T_{e} \omega_{k}}{L_{s}}} \\
& {\left[\begin{array}{cc}
-\psi_{\beta k}(k) & \psi_{\alpha k}(k) \\
\psi_{\alpha k}(k) & \psi_{\beta k}(k)
\end{array}\right]} \\
& {\left[\begin{array}{c}
v_{t \alpha k}(k)+\omega_{k} \psi_{\beta k}(k) \\
v_{t \beta k}(k)-\omega_{k} \psi_{\alpha k}(k)
\end{array}\right]}
\end{aligned}
$$

where $e_{p k}(k)$ and $e_{q k}(k)$ are the errors of the active and reactive power respectively, defined by Eqs. (16) and (17)

$e_{p k}(k)=P_{k_{-} r e f}(k)-P_{k}(k)$

$e_{q k}(k)=Q_{k_{-} r e f}(k)-Q_{k}(k)^{*}$

So, the required average voltage vector is expressed as follows

$$
\begin{aligned}
{\left[\begin{array}{c}
v_{t \alpha k}(k) \\
v_{t \beta k}(k)
\end{array}\right] } & =\frac{-1}{\psi_{\alpha k}^{2}+\psi_{\beta k}^{2}}\left[\begin{array}{cc}
\psi_{\beta k}(k) & -\psi_{\alpha k}(k) \\
-\psi_{\alpha k}(k) & -\psi_{\beta k}(k)
\end{array}\right] \\
& \left(\frac{L_{s}}{T_{e} \omega_{k}}\left[\begin{array}{c}
e_{p k}(k)+\Delta P_{k_{-} r e f}(k) \\
e_{q k}(k)+\Delta Q_{k_{-} r e f}(k)
\end{array}\right]+L_{s}\left[\begin{array}{c}
Q_{k}(k) \\
-P_{k}(k)
\end{array}\right]\right) \\
& -\omega_{k}\left[\begin{array}{c}
\psi_{\beta k}(k) \\
-\psi_{\alpha k}(k)
\end{array}\right] .
\end{aligned}
$$

\section{Five-level space vector modulation with balanced strategy}

In a five-level T-type converter, there are 125 possible switch combinations. The switch combinations are represented by ordered sets $\left(S_{a} S_{b} S_{c}\right)$, where $S_{a, b, c} \in\{0,1,2,3,4\}$ are the states of the converter's leg.

As shown in Fig. 3, all the 125 switching vectors can be sorted into four centered hexagons. The diagram of space vectors can be divided into six sectors with every sector further divided into sixteen triangles [30].

Projection of three-phase reference voltages into the $\alpha \beta$ plane is a vector called the reference voltage vector $v^{*}$; it rotates counter-clockwise with angular frequency of $\omega_{k}$ as shown in Fig. 3.

A five-level SVM is a discrete type of modulation technique in which a voltage reference vector $\boldsymbol{v}_{k}^{*}$ (computed by predictive direct power control algorithm) is synthesized by the time average of a number of appropriate switching state vectors [28]. When the reference voltage vector is located in a known sector at any sampling period, the tip of the voltage vector lies in a triangle formed by the three switching vectors adjacent to it, (see Fig. 3). 


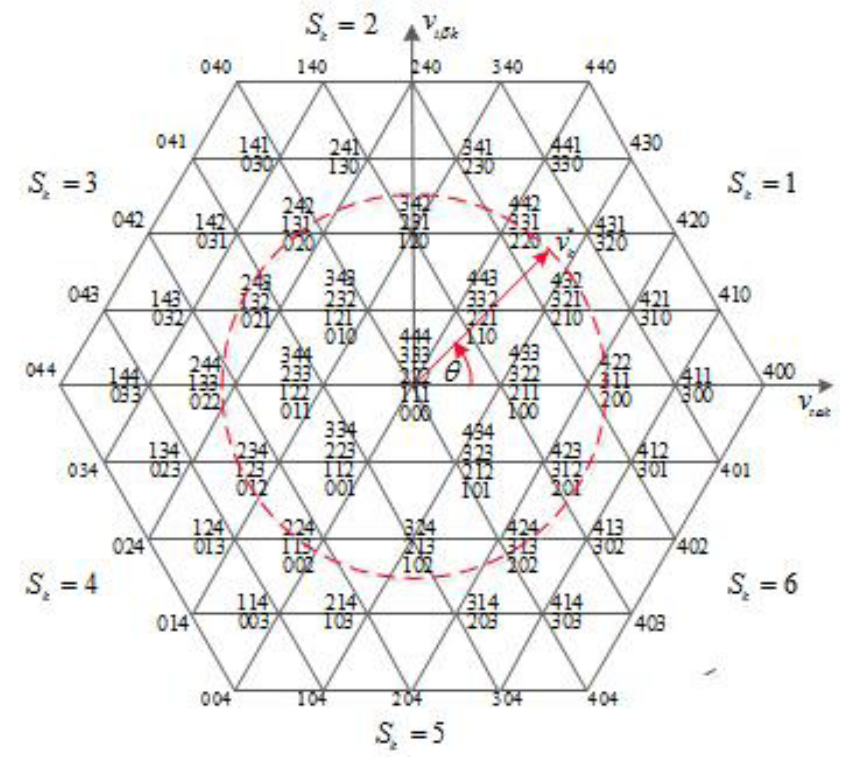

Fig. 3 Space voltage vectors for a five-level T-type converter

The adjacent vectors necessary to synthesize the reference voltage vector are related by

$\boldsymbol{v}_{1} t_{1}+\boldsymbol{v}_{2} t_{2}+\boldsymbol{v}_{3} t_{3}=\boldsymbol{v}_{k}^{*} T_{e}$

$t_{3}+t_{3}+t_{3}=T_{e}$

where $T_{s}$ is the switching period, $v_{1}, v_{2}$ and $v_{3}$ are the switching vectors adjacent to the reference voltage vector, and $t_{1}$, $t_{2}$ and $t_{3}$ are their on-duration time intervals, respectively.

Then to build the reference voltage vector $\boldsymbol{v}_{k}^{*}$, the fivelevel SVM has three main steps [29, 30]:

- Determination of the space vector location.

- Duration time calculation.

- Pulses generation.

In the five-level T-type converter, the voltages of the four series-connected DC-link capacitors must be confined to $V_{d c k} / 4$ to take advantage of the five-level T-type converter. The DC-voltage PI controller regulates only the total DC voltage $V_{d c k}$. For this reason, the DC-capacitor voltages are kept equals using five-level SVM that takes advantages of redundant switching states to counteract the DC voltages drift phenomenon [30].

The adopted control method used to balance the DC capacitor voltages is called the minimum energy property [9]. The balancing algorithm selects a combination of three adjacent redundant switching vectors that minimize the total energy stored in the DC-link capacitors; this energy reaches its minimum when all capacitor voltages are balanced [30].

\section{Simulation results}

In Section 5, both VF-DPC and proposed VF-PDPC of the VSC-MTDC system were simulated using Matlab $^{\mathrm{TM}} /$ Simulink environment using the parameters gathered in Table 2 .

Two simulations scenario have been performed to evaluate the system operation:

1. active power changes and

2. disconnection of the second unit.

The active power reference values of the wind farms are modeled by nonlinear functions, in order to emulate those generated from real wind variations.

\subsection{Case 1: Variation of reference power}

Fig. 4 shows dynamic responses of the DC-link voltages of VSC based MTDC transmission system. The DC voltage of the MTDC system remains around its reference value, and does not impacted by the active power variations in both control strategies.

In Fig. 5, both first and second units inject an active power about $100 \mathrm{MW}$ to the DC grid, whereas the reactive powers of all units are kept at theirs null values to achieve a unity power factor operation. It is clearly shown that the active and reactive power track their respective references quickly and accurately in both control methods. However, the active and reactive power ripples are smaller using the proposed VF-PDPC.

From Fig. 6, it can be seen that the DC capacitor voltages are balanced at their reference values with small ripple which confirms the effectiveness of the five-level SVM equipped with balancing strategy.

Table 2 Simulation parameters

\begin{tabular}{lc}
\hline Parameter & Value \\
\hline Rated power & $200 \mathrm{MW}$ \\
Source voltage $V_{s k_{-} \text {ref }}$ & $10 \mathrm{kV}$ \\
DC-link voltage $V_{d c_{-} \text {ref }}$ & $25 \mathrm{kV}$ \\
Frequencies of the grid $f_{1}, f_{2}, f_{3}$ & $60 \mathrm{~Hz}, 60 \mathrm{~Hz}, 50 \mathrm{~Hz}$ \\
Line impedance $R_{s}, L_{s}$ & $0.04 \Omega, 0.006 \mathrm{H}$ \\
DC-link capacitance $C_{k j}$ & $500 \mu \mathrm{F}$ \\
Cable length & $100 \mathrm{~km}$ \\
Cable resistance $r_{d c}$ & $0.699 \Omega / \mathrm{km}$ \\
Cable inductance $l_{d c}$ & $0.19 \mathrm{mH} / \mathrm{km}$ \\
Cable capacitance $c_{d c}$ & $308 \mu \mathrm{F} / \mathrm{km}$ \\
\hline
\end{tabular}



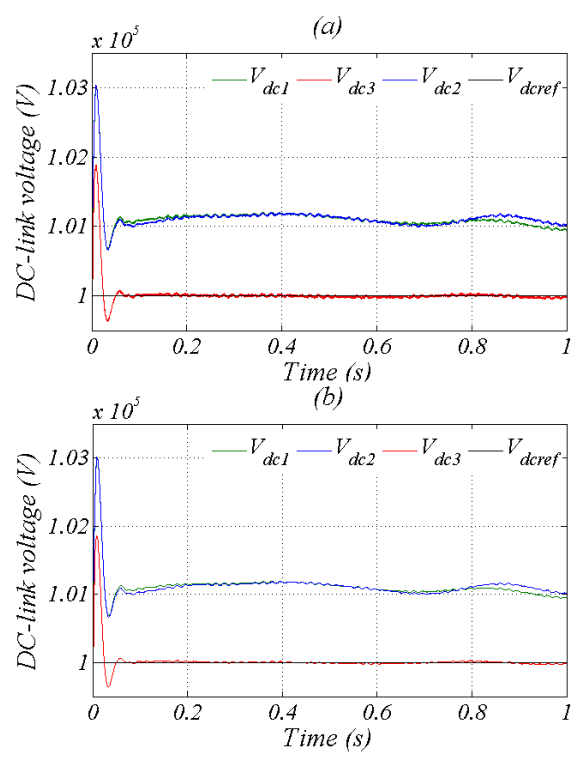

Fig. 4 Simulation results of DC-links voltages:

(a) with VF-DPC-SVM control, (b) with VF-PDPC-SVM control

The total harmonic distortion (THD) values of AC side currents of all units for both VF-DPC and VF-PDPC are presented in Fig. 7. It can be noticed that the line currents THD obtained with VF-DPC are $1.35 \%, 1.34 \%$ and $0.96 \%$ for Unit1, Unit2, and Unit3, respectively. However, with the proposed VF-PDPC the line currents THD are reduced to $0.75 \%, 0.76 \%$ and $0.18 \%$, respectively, which prove the effectiveness of the proposed VF-PDPC over VF-DPC for this operating condition.

\subsection{Case 2: Unit disconnection}

In this test, at instant $t=0.5 \mathrm{~s}$, the first unit is disconnected, whereas the second unit remains injecting the same power level. Fig. 8 indicates that the DC voltage of each terminal is maintained close to its reference even after the Unit1 disconnection.

Fig. 9 presents active and reactive power exchange of all terminals after Unitl disconnection. As it is expected, the injected active power by the first unit is stepped down from $100 \mathrm{MW}$ to 0 , while the reactive power was kept null with a significant fluctuations when the traditional VF-DPC is used (see Fig. 9 (b)). However, it is clear that the proposed VF-PDPC presents much lower power ripples. Indeed, the first unit reactive power ripples are significantly reduced.

\section{Conclusion}

The purpose of this paper was to present a theoretical study with simulation of virtual flux predictive direct power control for a five-level T-type multi-terminal transmission system.
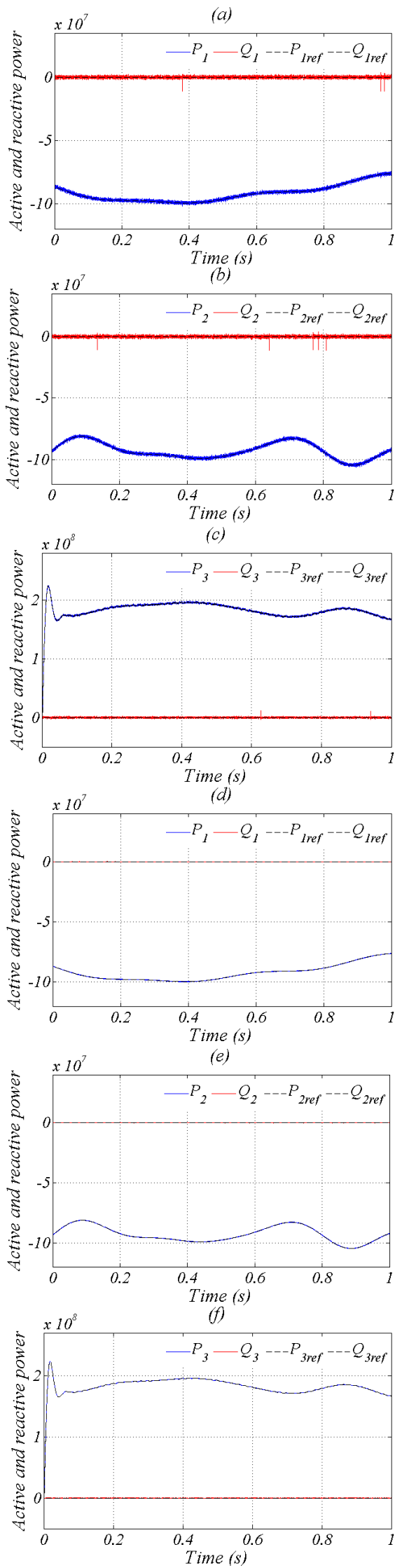

Fig. 5 Simulation results of active and reactive power: (a)-(c) with VF-DPC-SVM control, (d)-(f) with VF-PDPC-SVM control 


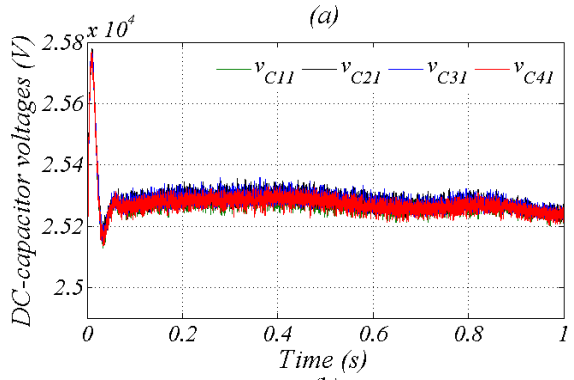

(b)
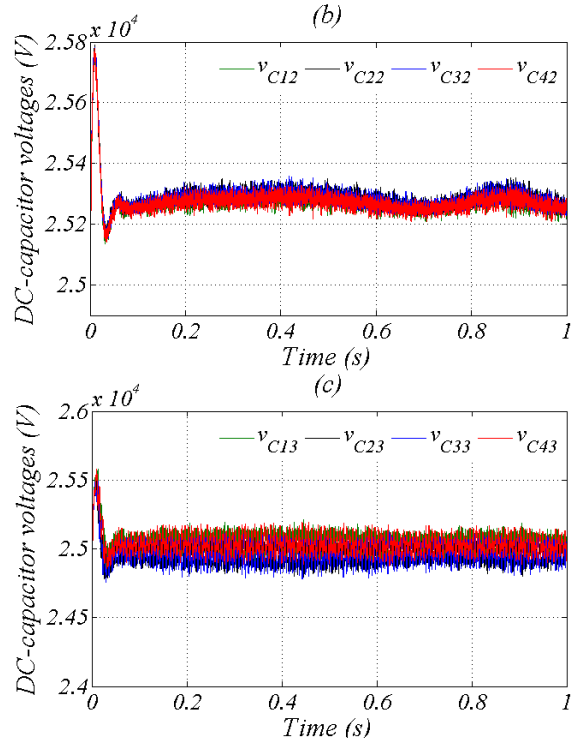

(d)

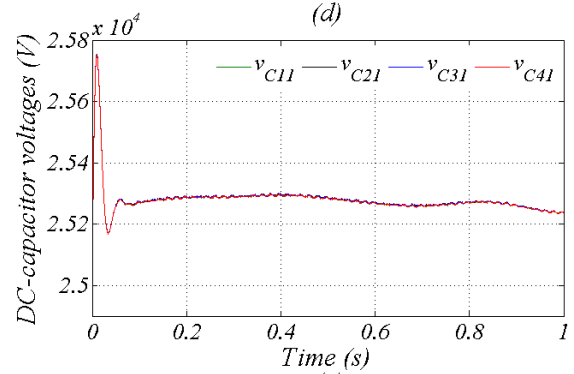

(e)

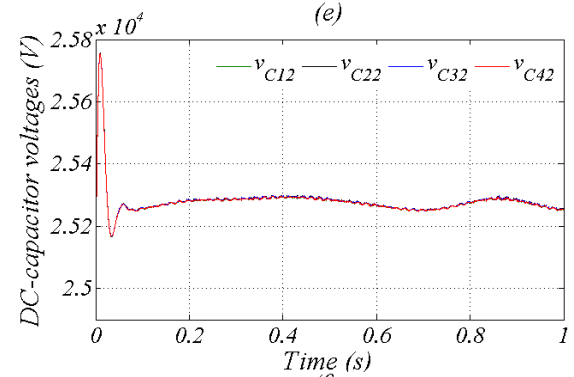

$(f)$

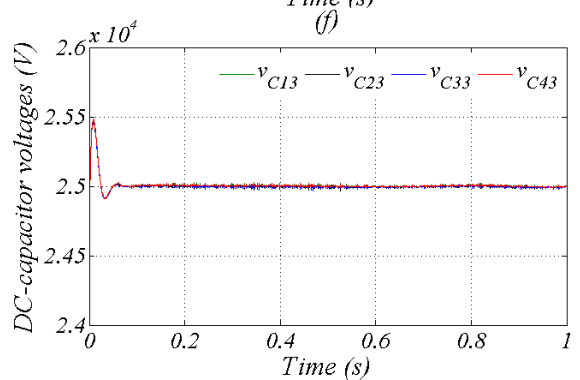

Fig. 6 Simulation results of DC capacitors voltages:

(a)-(c) with VF-DPC-SVM control,

(d)-(f) with VF-PDPC-SVM control (a) Fundamental $(60 \mathrm{~Hz})=2404, \mathrm{THD}=1.35 \%$

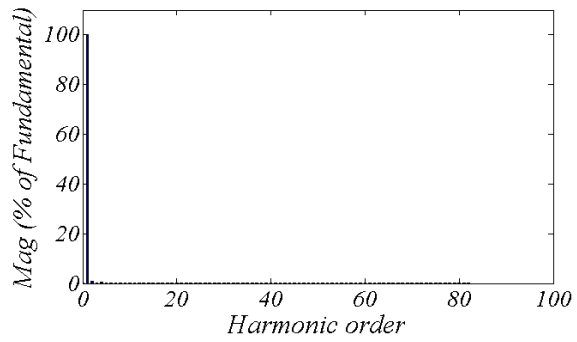

(b) Fundamental $(60 \mathrm{~Hz})=2136, \mathrm{THD}=1.34 \%$

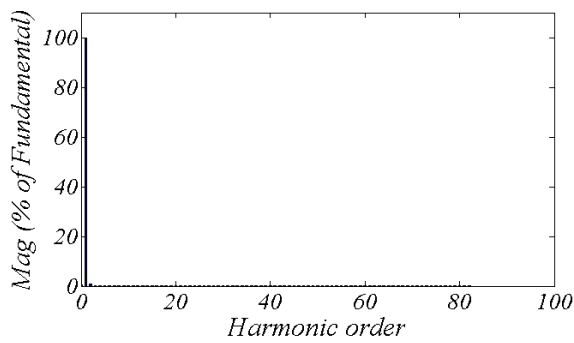

(c) Fundamental $(50 \mathrm{~Hz})=4420, \mathrm{THD}=0.96 \%$

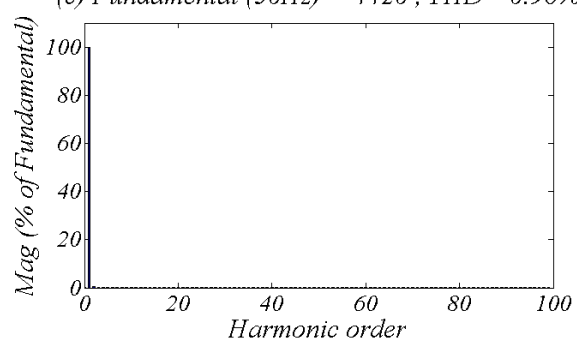

(d) Fundamental $(60 \mathrm{~Hz})=2440, T H D=0.76 \%$

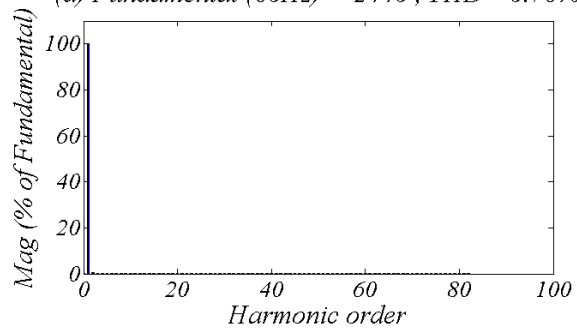

(e) Fundamental $(60 \mathrm{~Hz})=2376, \mathrm{THD}=0.75 \%$

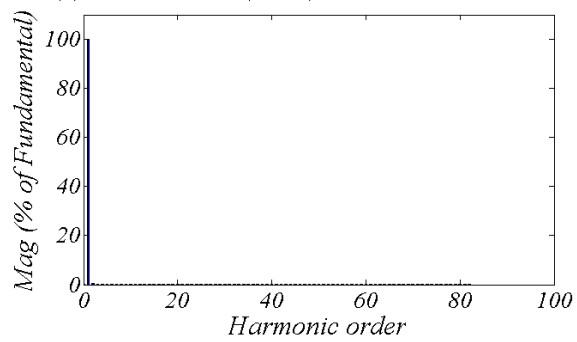

(f) Fundamental $(50 \mathrm{~Hz})=4696, T H D=0.18 \%$

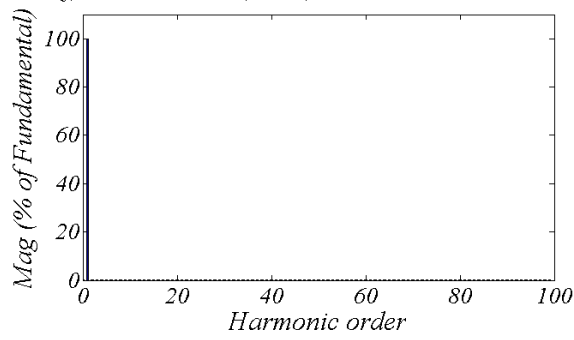

Fig. 7 Total harmonic distortion (THD) of line currents: (a)-(c) with VF-DPC-SVM control, (d)-(f) with VF-PDPC-SVM control 

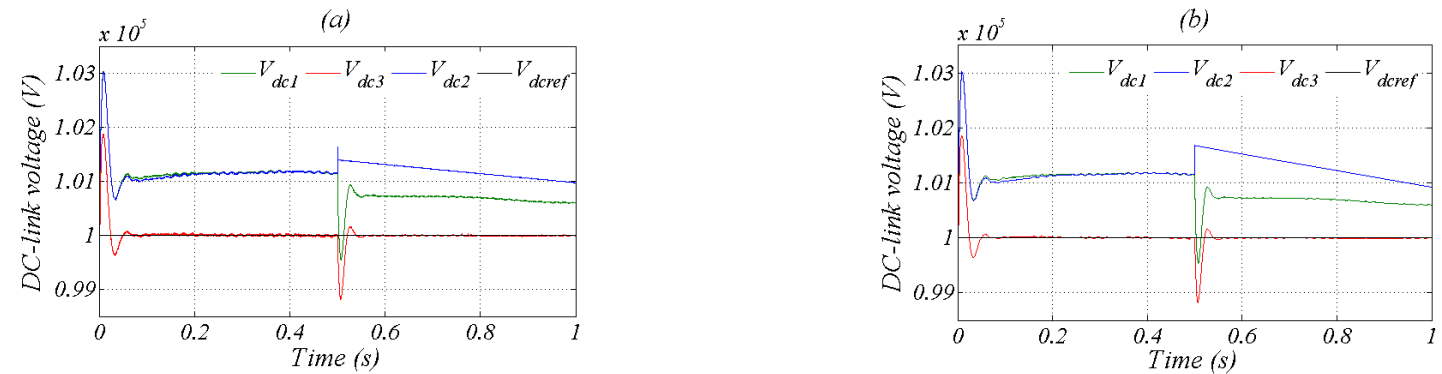

Fig. 8 Simulation results of DC-links voltages during converter disconnection: (a) with VF-DPC-SVM control (b) with VF-PDPC-SVM control
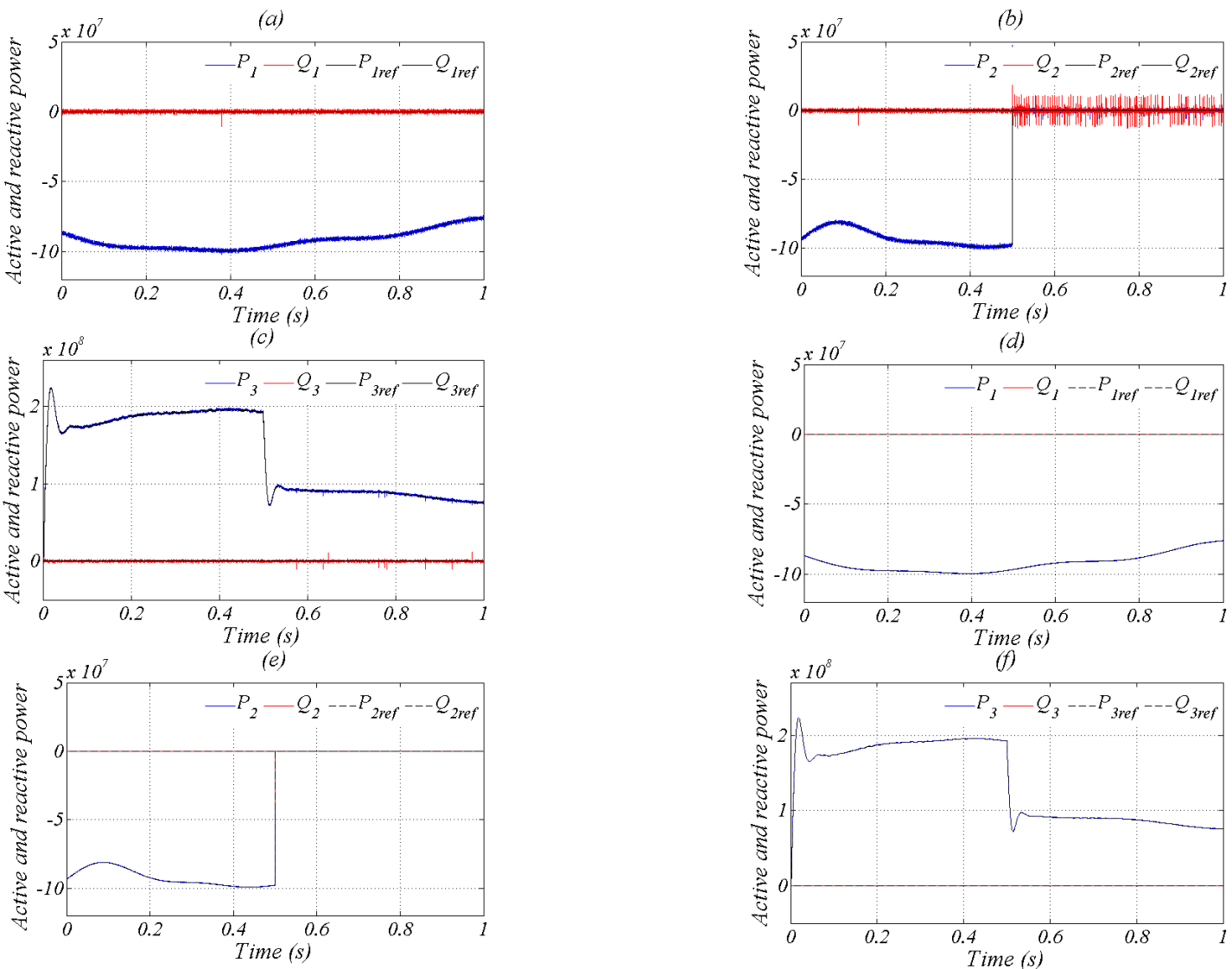

Fig. 9 Simulation results of active and reactive power during the first unit disconnection:

(a)-(c) with VF-DPC-SVM control, (d)-(f) with VF-PDPC-SVM control

The VF-PDPC is based on the virtual flux predictive control algorithm to deliver the average voltage vector, which ensures a good and accurate regulation of active and reactive power. One can see that the proposed VF-PDPC control algorithm is simple since the coordinate transformation, current regulation loops, and $\mathrm{AC}$ voltage sensors are not required. Furthermore, thanks to

\section{References}

[1] Silva, A. S., Santos, R. C., Torres, J. A., Coury, D. V. "An accurate method for fault location in HVDC systems based on pattern recognition of DC voltage signals", Electric Power Systems Research, 170, pp. 64-71, 2019.

https://doi.org/10.1016/j.epsr.2019.01.013 the five-level SVM application a constant switching frequency is achieved.

The simulation results prove that the proposed control strategy gives high performance of the multi-terminal VSC-MTDC transmission system compared with traditional VF-DPC in terms of powers flow, grid current waveforms quality and active and reactive power ripples.

[2] Chu, X. "Unbalanced current analysis and novel differential protection for HVDC transmission lines based on the distributed parameter model", Electric Power Systems Research, 171, pp. 105-115, 2019.

https://doi.org/10.1016/j.epsr.2019.02.003 
[3] Castro, L. M., Tovar-Hernández, J. H., González-Cabrera, N., Rodríguez-Rodríguez, J. R. "Real-power economic dispatch of AC/ DC power transmission systems comprising multiple VSC-HVDC equipment", International Journal of Electrical Power \& Energy Systems, 107, pp. 140-148, 2019. https://doi.org/10.1016/j.ijepes.2018.11.018

[4] Gil-González, W., Montoya, O. D., Garces, A. "Direct power control for VSC-HVDC systems: An application of the global tracking passivity-based PI approach", International Journal of Electrical Power and Energy Systems, 110, pp. 588-597, 2019. https://doi.org/10.1016/j.ijepes.2019.03.042

[5] Zeng, L., Yao, W., Zeng, Q., Li, D., Fang, J., Ai, X., Wen, J., He, H. "Design and real-time implementation of data-driven adaptive wide-area damping controller for back-to-back VSC-HVDC", Electrical Power \& Energy Systems, 109, pp. 558-574, 2019. https://doi.org/10.1016/j.ijepes.2019.02.024

[6] Mohan, M., Panduranga Vittal, K. "DC Fault Protection in Multiterminal VSC-Based HVDC Transmission Systems with Current Limiting Reactors", Journal of Electrical Engineering \& Technology, 14(1), pp. 1-12, 2019. https://doi.org/10.1007/s42835-018-00027-3

[7] Gavriluta, C., Candela, I., Citro, C., Luna, A., Rodriguez, P. "Design considerations for primary control in multi-terminal VSC-HVDC grids", Electric Power Systems Research, 122, pp. 33-41, 2015. https://doi.org/10.1016/j.epsr.2014.12.020

[8] Khazaei, J., Idowu, P., Asrari, A., Shafaye, A. B., Piyasinghe, L. "Review of HVDC control in weak AC grids", Electric Power Systems Research, 162, pp. 194-206, 2018. https://doi.org/10.1016/j.epsr.2018.05.022

[9] Reguig Berra, A., Barkat, S., Bouzidi, M. "Virtual flux direct power-backstepping control of 5-level T-type multiterminal VSCHVDC system", International Transactions on Electrical Energy Systems, 27(9), Article number: e2352, 2017. https://doi.org/10.1002/etep.2352

[10] Jamali, S., Mirhosseini, S. S. "Protection of transmission lines in multi-terminal HVDC grids using travelling waves morphological gradient", Electrical Power and Energy Systems, 108, pp. 125-134, 2019.

https://doi.org/10.1016/j.ijepes.2019.01.012

[11] Wang, P., Zhang, X. P., Coventry, P. F., Zhang, R., Li, Z. "Control and protection sequence for recovery and reconfiguration of an offshore integrated MMC multi-terminal HVDC system under DC faults", International Journal of Electrical Power \& Energy Systems, 86, pp. 81-92, 2017.

https://doi.org/10.1016/j.ijepes.2016.10.003

[12] Saeedifard, M., Iravani, R., Pou, J. "A Space Vector Modulation Strategy for a Back-to-Back Five-Level HVDC Converter System", IEEE Transactions onIndustrail Electronics, 56(2), pp. 425-466, 2009.

https://doi.org/10.1109/TIE.2008.2008360

[13] Chaves, M., Margato, E., Silva, J. F., Pinto, S. F., Santana, J. "HVDC transmission systems: Bipolar back-to-back diode clamped multilevel converter with fast optimum-predictive control and capacitor balancing strategy", Electric Power System Research, 81(7), pp. 1436-1445, 2011

https://doi.org/10.1016/j.epsr.2011.02.008
[14] Chennai, S. "Efficient Control Scheme for Five-level (NPC) Shunt Active Power Filters Based on Fuzzy Control Approaches", Periodica Polytechnica Electrical Engineering and Computer Science, 60(2), pp. 135-142, 2016.

https://doi.org/10.3311/PPee.9015

[15] Nguyen, T. D., Dzung, P. Q., Dat, D. N., Nhan, N. H. "The carrierbased PWM method to reduce common-mode voltage for threelevel T-type neutral point clamp inverter", In: 2014 9th IEEE Conference on Industrial Electronics and Applications (ICIEA), Hangzhou, China, 2014, pp. 1549-1554. https://doi.org/10.1109/ICIEA.2014.6931415

[16] Ounejjar, Y., Al-Haddad, K., Gregoire, L. A. "Packed U Cells Multilevel Converter Topology: Theoretical Study and Experimental Validation", IEEE Transactions on Industrial Electronics, 58(4), pp. 1294-1306, 2011. https://doi.org/10.1109/TIE.2010.2050412

[17] Rajanand Patnaik, N., Ravindranath Tagore, Y., Chaitanya, S. "Advanced seven level transformer-less multilevel inverter topology for PV application", In: 2017 Third International Conference on Advances in Electrical, Electronics, Information, Communication and Bio-Informatics (AEEICB), Chennai, India, 2017, pp. 111-116. https://doi.org/10.1109/AEEICB.2017.7972393

[18] Rajanand Patnaik, N., Ravindranath Tagore, Y. "Design and Evaluation of PUC (Packed U Cell) Topology at Different Levels \& Loads in Terms of THD", European Journal of Advances in Engineering and Technology, 3(9), pp. 33-43, 2016.

[19] Narasipuram, R. P., Yadlapalli, R. T. "Performance analysis and design optimisation of 3-Ø Packed U Cell inverter for industrial drive applications", International Journal of Mathematical Modelling and Numerical Optimisation (IJMMNO), 9(3), pp. 309-337, 2019. https://doi.org/10.1504/IJMMNO.2019.100518

[20] Narasipuram, R. P. "Optimal design and analysis of hybrid photovoltaic-fuel cell power generation system for an advanced converter technologies", International Journal of Mathematical Modelling and Numerical Optimisation (IJMMNO), 8(3), pp. 245-276, 2018 https://doi.org/10.1504/IJMMNO.2018.088990

[21] Cacau, R. G. A., Bascopé, R. P. T., Neto, J. A. F., Bascopé, G. V. T. "Five-level T-type inverter based on multistate switching cell", In: 2012 10th IEEE/IAS International Conference on Industry Application, Fortaleza, Brazil, 2012, pp. 1-8. https://doi.org/10.1109/INDUSCON.2012.6453728

[22] Schweizer, M., Kolar, J. W. "Design and Implementation of aHighly Efficient Three-Level T-Type Converter for Low-Voltage Applications", IEEE Transactions on Power Electronics, 28(2), pp. 899-907, 2013. https://doi.org/10.1109/TPEL.2012.2203151

[23] Cheah-Mane, M., Sainz, L., Prieto-Araujo, E., Gomis-Bellmunt, O. "Impedance-based analysis of harmonic instabilities in HVDCconnected Offshore Wind Power Plants", International Journal of Electrical Power \& Energy Systems, 106, pp. 420-431, 2019. https://doi.org/10.1016/j.ijepes.2018.10.031

[24] Zhou, Q., Ding, Y., Mai, K., Bian, X., Zhou, B. "Mitigation of subsynchronous oscillation in a VSC-HVDC connected offshore wind farm integrated to grid", Electrical Power \& Energy Systems, 109, pp. 29-37, 2019 https://doi.org/10.1016/j.ijepes.2019.01.031 
[25] Khazaei, J., Miao, Z., Piyasinghe, L., Fan, L. "Minimizing DC system loss in multi-terminal HVDC systems through adaptive droop control", Electric Power System Research, 126, pp. 78-86, 2015. https://doi.org/10.1016/j.epsr.2015.04.020

[26] Malinowski, M., Kazmierkowski, M. P., Hansen, S., Blaabjerg, F., Marques, G. D. "Virtual-flux-based direct power control of three-phase PWM rectifiers", IEEE Transactions on Industry Applications, 37(4), pp. 1019-1027, 2001. https://doi.org/10.1109/28.936392

[27] Bouafia, A., Gaubert, J. P., Krim, F. "Predictive Direct Power Control of Three-Phase PulsewidthModulation (PWM) Rectifier Using Space-Vector Modulation (SVM)", IEEE Transactions on Power Electronics, 25(1), pp. 228-236, 2010.

https://doi.org/10.1109/TPEL.2009.2028731
[28] Antoniewicz, P., Kazmierkowski, M. P. "Virtual-Flux-Based Predictive Direct Power Control of AC/DC Converters With Online Inductance Estimation", IEEE Transactions on Industrial Electronics, 55(12), pp. 4381-4390, 2008. https://doi.org/10.1109/TIE.2008.2007519

[29] Hotait, H. A., Massoud, A. M., Finney, S. J., Williams, B. W. "Capacitor voltage balancing using redundant states of space vector modulation for five-level diode clamped inverters", IET Power Electronics, 3(2), pp. 292-313, 2010. https://doi.org/10.1049/iet-pel.2008.0327

[30] Saeedifard, M., Iravani, R., Pou, J. "Control and DC-capacitor voltage balancing of a space vector-modulated five-level STATCOM", IET Power Electronics, 2(3), pp. 203-215, 2009. https://doi.org/10.1049/iet-pel.2008.0021 